\title{
ATUAÇÃO DO ENFERMEIRO NA FORMAÇÃO DO INSTRUTOR DE TRÂNSITO
}

\author{
Luís Felipe Pissaia ${ }^{1}$ \\ Éder Luís Arboit ${ }^{2}$
}

Resumo: Estudo descritivo que objetivou relatar a experiência de enfermeiros na inserção da disciplina de medicina de tráfego e primeiros socorros em um curso de formação de instrutores de trânsito. A atuaçáo do enfermeiro como docente se configura como essencial, uma vez que proporcionam conhecimentos diretamente relacionados à prática profissional, promovendo subsídios teóricopráticos para a promoção de um trânsito mais seguro, açóes de prevenção de acidentes e de primeiros socorros, além da redução de agravos às vítimas.

Palavras-chave: Saúde e Segurança; Segurança no Trânsito; Condutores de Veículos.

\section{ROLE OF THE NURSE IN THE TRAINING OF THE TRAFFIC INSTRUCTOR}

\begin{abstract}
Descriptive study, which aimed to report the experience of nurses in the insertion of the discipline of traffic medicine and first aid in a training course for traffic instructors. The role of the nurse as a teacher is essential, as it provides knowledge directly related to professional practice, promoting theoretical and practical subsidies for the promotion of safer traffic, accident prevention and first aid actions, in addition to the reduction of grievances to victims.
\end{abstract}

Keywords: Health and safety; Traffic Safety; Vehicle Drivers.

\section{INTRODUÇÃO}

A correlação entre saúde e trânsito está intimamente ligada com a qualidade de vida e o bem-estar da população em geral. Desta forma Adura Gianvecchio e Munoz (2012) destacam a necessidade de articular açóes educativas em prol deste

1 Enfermeiro, Mestre e Doutorando em Ensino. Docente na Universidade do Vale do Taquari Univates. E-mail: lpissaia@universo.univates.br

2 Enfermeiro, Mestre e Doutorando em Enfermagem PPGEnf/UFSM. Docente na Universidade de Cruz Alta - UNICRUZ. E-mail: earboit@unicruz.edu.br 
conhecimento para a população em geral. Segundo Goi e Goi (2020), a condução de veículos automotores, bem como a livre utilização das vias públicas, exige a compreensão por parte dos condutores e pedestres acerca das legislaçóes vigentes e a capacidade de discernimento sobre os direitos e deveres do cidadão.

Nesta direção, a saúde está intimamente ligada com a educação no trânsito e conforme Pissaia e Costa (2020) é parte fundamental da formação do instrutor de trânsito. Este profissional é responsável pela formação dos futuros condutores de veículos. Ainda, segundo Alves Júnior (2010) o instrutor de trânsito desempenha a autoridade frente ao assunto, sendo responsável por ministrar cursos, desenvolver açôes de prevenção de acidentes e oferecer o apoio necessário para a capacitação da população nos mais diversos espaços, sejam eles no âmbito da sala de aula ou fora dela.

Conforme Mello (2017), o instrutor de trânsito é o profissional responsável por conduzir as aulas teóricas e práticas dos cursos de formação de condutores de veículos, não somente capacitando, mas ensinando os primeiros passos dos cidadãos frente à utilização compartilhada das vias. Ainda, para Corrêa (2017), o aumento exponencial no número de acidentes de trânsito é fruto de negligências e imprudências por parte dos condutores, fazem fazendo com que os órgãos de fiscalização governamentais invistam ainda mais na formação crítica e reflexiva dos indivíduos sobre o meio.

A formação do instrutor de trânsito segue algumas determinações que mapeiam as necessidades loco regionais em relação às legislações e costumes da população. Para Moreira (2010), as bases teóricas e práticas são subdivididas em módulos que desenvolvem a cultura de segurança frente à atuaçáo profissional. Em meio ao currículo de formaçáo do instrutor de trânsito, há a disciplina de medicina de tráfego e primeiros socorros, cujo principal viés de existência é orientar os futuros profissionais sobre a necessidade do bem-estar do indivíduo, reconhecer situaçóes de risco e realizar ações que tratem de cuidados a possíveis vítimas (PISSAIA; COSTA, 2019).

Destaca-se aqui o importante papel que o enfermeiro desempenha nas ações de educação, saúde e segurança, de modo a proporcionar subsídios para a adoção de um uma direção mais segura no trânsito. Perez et al. (2018) destacam ainda que a atuação do enfermeiro pode influenciar de maneira positiva a redução das taxas de morbimortalidade por trauma ou violências, inclusive no ambiente pré-hospitalar e em acidentes de trânsito. Assim, o conhecimento solidificado e a tomada de decisão qualificada podem influenciar nos primeiros socorros adotados na cena do acidente, no transporte ao serviço de saúde de referência e nos desfechos finais na vida de pedestres e condutores.

Segundo Pissaia e Costa (2020) a presença da disciplina de medicina de tráfego e primeiros socorros na formação do instrutor de trânsito é fundamental para os estudantes desenvolverem uma noção clara sobre a saúde e a sua aplicabilidade em prol do bem-estar da população. Sob o mesmo limiar, Carneiro e Faria (2017) argumentam que o sucesso na formação dos condutores de veículos vem à tona 
a partir das próprias experiências que o instrutor recebe enquanto acadêmico, interligando a teoria com a prática e criando vínculo entre os pontos.

Desta forma, o objetivo do estudo consiste em relatar a experiência de enfermeiros na inserção da disciplina de medicina de tráfego e primeiros socorros em um curso de formação de instrutores de trânsito.

\section{MATERIAIS E MÉTODOS}

Trata-se de um relato de experiência, descritivo e exploratório. A pesquisa teve como participantes, 13 estudantes da disciplina de medicina de tráfego e primeiros socorros de um curso de formação em instrutor de trânsito de uma Instituição de Ensino Superior (IES) do interior do estado do Rio Grande do Sul, Brasil.

A coleta de dados ocorreu durante o mês de junho do ano de 2021, utilizando como instrumento de pesquisa, um questionário semiestruturado. $\mathrm{O}$ questionário foi aplicado presencialmente ao final da disciplina de medicina de tráfego e primeiros socorros que compóe o currículo de formação do instrutor de trânsito. O instrumento buscou identificar as percepçóes dos participantes sobre a referida disciplina. Em posse dos questionários, os pesquisadores transcreveram os mesmos individualmente em um documento digital para edição de texto. Após, as informaçóes coletadas foram analisadas integralmente e reunidas por pontos focais compatíveis. Os três principais pontos focais identificados foram: construção da disciplina, atuação do profissional e espaço de ensino do instrutor de trânsito. Cada ponto focal deu origem em uma categoria temática abordada e discutida na semana seguinte. Ressalta-se que este processo de análise segue aproximaçóes com a Análise de Conteúdo proposta por Bardin (2016).

Para a realizaçáo da pesquisa foram respeitados todos os aspectos da Resolução 466/2012 do Conselho Nacional de Saúde. Compondo ainda a atenção ética ao processo, no início do módulo de medicina de tráfego e primeiros socorros, o docente explicou os objetivos do estudo, bem como sanou todas as dúvidas dos participantes. No mesmo momento foi entregue o Termo de Consentimento Livre e Esclarecido (TCLE), o qual os participantes realizaram a leitura, sinalizaram o interesse em participar do estudo e assinaram em duas vias de igual teor, uma para o participante e outra para o pesquisador. $\mathrm{O}$ total de 13 estudantes da turma pesquisada indicou que gostariam de participar do estudo e para cada um foi utilizado um codinome, sendo a siga "IT", numerado aleatoriamente em substituição ao nome próprio.

\section{RESULTADOS E DISCUSSÓES}

Esta seção é responsável por apresentar os resultados e as discussôes pertinentes ao leitor. A primeira subseção apresenta os detalhes da disciplina estudada, sendo intitulada como "Construçáo da disciplina de Medicina de tráfego e primeiros socorros". A segunda subseção demonstra as percepçóes dos participantes sobre a aplicabilidade dos conteúdos, denominada como "Medicina de tráfego e primeiros socorros: aplicação prática". E por fim, o perfil de formação do instrutor de trânsito 
é explorado no contexto da atuaçáo perante a comunidade na subseçáo indicada como "O instrutor de trânsito enquanto formador de condutores".

\section{Construçáo da disciplina de medicina de tráfego e primeiros socorros}

Esta subseção apresenta a construção da disciplina de medicina de tráfego e primeiros socorros no curso de formação de instrutor de trânsito, para tal será discutido a sua inserção curricular, bem como os detalhes que compóem a sua ementa.

A formação do instrutor de trânsito é ampla e direcionada a observar os problemas da sociedade contemporânea, principalmente aqueles relacionados à formação segura de condutores, conforme indica Araújo (2014). Desta forma, a composição de módulos e disciplinas segue intrinsecamente a forma de atingir tais objetivos e necessidades constantes no curso, intuindo metodologicamente sobre o contexto ao qual o profissional estará inserido (PISSAIA; COSTA, 2019).

O curso de formação da IES estudada possui 180 horas distribuídas em seis módulos, com atividades teóricas e práticas. Entre os temas abordados destaca-se: legislação, cuidado ao meio ambiente, saúde e autocuidado, mecânica, atividades práticas veiculares e estágios nas áreas. A disciplina de medicina de tráfego e primeiros socorros é a última do quarto módulo que compóe o currículo de formação, possuindo um total de 12 horas aula entre os conteúdos teóricos e práticos.

A construção da disciplina em si, seguiu o limiar metodológico que contempla a teoria e a prática dos temas de medicina de tráfego e primeiros socorros. As primeiras quatro horas de aulas teóricas contemplam o estudo das questóes relacionadas à cinemática e epidemiologia do trauma, medicina de tráfego, processo de saúde e doença e a transversalidade com a segurança no trânsito.

Conforme Mello (2017) a formaçáo do instrutor de trânsito necessita de reflexóes pertinentes ao meio, às possibilidades de mudança e de intervenção na comunidade, com açôes educativas, mas também voltadas para a melhoria da qualidade de vida da população. Ainda, para Pissaia e Costa (2020), a relação entre saúde e trânsito merecem destaque e atenção especial para a formação do profissional, indicando ainda as práticas de educação em saúde como essenciais para a atuação.

Dessa forma, nas quatro horas restantes, abordaram-se os aspectos relacionados à avaliação da cena e do indivíduo/vítima, com especial enfoque nos sinais/sintomas clínicos, bem como a identificação de intercorrências e condutas a serem adotadas. Parte da carga horária ainda é dedicada ao entendimento dos parâmetros que compóem os cinco sinais vitais: pressão arterial, frequência cardíaca, frequência respiratória, temperatura corporal e dor, bem como a prática de aferição de cada um dos indicativos.

Para Alves Júnior (2010), o conteúdo de medicina de tráfego é a base para as reflexões do instrutor de trânsito perante as necessidades dos indivíduos ao seu redor, tanto alunos quanto potenciais vítimas de traumas. Ainda, Fenelon et al. 
(2012) indicam que as noções de medicina de tráfego são essenciais ao indivíduo, responsabilizando o mesmo sobre o bem-estar e a segurança que exerce sobre o trânsito a partir do quesito saúde, fortalecendo não só a sobrevida de vítimas, mas conferindo uma abordagem educativa ao cenário.

E por fim, a última parte da disciplina, ou seja, as últimas quatro horas aula foram reservadas ao conteúdo teórico e prático de primeiros socorros. Dentre os conteúdos abordados destacam-se: fraturas, quedas, acidentes de trânsito diversos, mal súbito, desmaio, convulsões, parada cardiorrespiratória e engasgo, e também acidentes com substâncias químicas, queimaduras e picadas de animais. Cada conteúdo teórico foi seguido pela realização de práticas com a turma, tendo como apoio os materiais e moldes humanos disponíveis na IES. Ao final desta aula, também foi aplicado o questionário, instrumento desta pesquisa.

Segundo Sousa Lima et al. (2021) a realização de primeiros socorros não é restrita aos profissionais da saúde especializados, pois todo e qualquer cidadão possui o dever de avaliar a vítima, chamar por socorro e ainda realizar alguma manobra em caso de estar capacitado para tal ação. Ainda, Morais et al. (2021) argumentam sobre a necessidade de realização de práticas diversas para a experimentação acadêmica quanto ao conteúdo básico de noçôes sobre primeiros socorros, angariando assim reflexóes sobre o tema e a fixação daquele conteúdo. Abaixo, na tabela 1, pode ser observada a organizaçáo de conteúdos subdivididos em suas respectivas cargas horária de aula.

Tabela 1. Organização da disciplina de medicina de tráfego e primeiros socorros.

\begin{tabular}{c|l}
\hline $\mathbf{C H}$ & \multicolumn{1}{c}{ CONTEÚDO } \\
\hline 4 horas & $\begin{array}{l}\text { Noçôes sobre medicina de tráfego; Mudança de hábitos e a necessidade para um trânsito } \\
\text { seguro; Reflexôes em grupo sobre saúde e segurança no trânsito. }\end{array}$ \\
\hline 4 horas & $\begin{array}{l}\text { Avaliação do indivíduo; Alterações nas funçóes vitais; Sinais vitais e suas aferiçóes; } \\
\text { Prática em duplas para aferição dos sinais vitais. }\end{array}$ \\
\hline 4 horas & $\begin{array}{l}\text { Primeiros socorros; Principais situações de risco para trauma ou mal súbito; Práticas em } \\
\text { grupo sobre primeiros socorros; Aplicação do questionário. }\end{array}$ \\
\hline
\end{tabular}

Fonte: Os autores (2021).

Ao observar a organizaçáo da disciplina, percebe-se que o docente amplia a visão de saúde para os estudantes, de modo que os mesmos consigam incorporar os conceitos relacionados ao processo de saúde e doença no cotidiano de trabalho do futuro instrutor de trânsito. A ampliaçáo do tema medicina de tráfego e primeiros socorros não indica somente a necessidade de qualificar a formação profissional, mas também na ideia de que o instrutor de trânsito participa ativamente do processo de formação dos futuros condutores junto ao Centro de Formação de Condutores (CFC), tanto em âmbito prático, quanto teórico. E, em assim sendo, promove uma cultura mais responsável, harmônica e cidadã entre pedestres e condutores. 


\section{Medicina de tráfego e primeiros socorros: aplicaçáo prática}

Nesta subseção é apresentado o contexto de percepçóes dos participantes sobre a presença do conteúdo de primeiros socorros em sua formação. Tal iniciativa busca identificar notoriamente a importância que fundamenta o ensino de primeiros socorros durante a formação do instrutor de trânsito.

Em suma, os participantes da pesquisa identificam que a realizaçáo de práticas de primeiros socorros na formação é importante por capacitar a atuação em caso de necessidade, principalmente em risco de vida. Tal achado pode ser verificado na descrição de IT 2: A contribuiçâao para o instrutor de trânsito é de relevância incrivel e indispensável, pois são práticas que podem salvar vidas. Sob o mesmo limiar, o participante IT7 cita: É importante, pois aprendemos muitas coisas com as noçóes de primeiros socorros e medicina de tráfego. O mesmo participante comenta ainda: Este módulo nos habilita a até mesmo salvar vidas. Desta forma, Silva et al. (2021) demonstram em seu estudo o potencial de inserção das práticas de primeiros socorros em cursos de formaçáo diversos como meio de qualificação na futura atuação individual ou coletiva.

Diante de tal perspectiva, a capacidade de saber lidar com situaçóes de risco ou perigo também aparece nos registros dos participantes da pesquisa, conforme indica IT10: Muito bom, pois nos auxilia a como lidar em situaçôes de acidentes, prevenindo e ajudando a contribuir para salvar pessoas. É interessante pensar que o participante cita a palavra "prevenção" em meio a situaçóes de saúde, conferindo assim segurança e autonomia neste cenário. Ainda, o participante IT1 relata:

\footnotetext{
Mostrando o que fazer, e o que não fazer, prezando pela segurança pessoal e em segundo lugar realizar tudo o que estiver ao alcance de salvar a vítima. Também é importante a caráter de conscientização, fazendo com que redobre os cuidados nas práticas diárias como instrutor (IT1).
}

Segundo Silva, Oyama e Sanches (2016) o ensino de primeiros socorros para a população em geral, gera a autonomia necessária para a tomada de decisão assertiva em momento de crise. Conforme Pereira et al. (2021), a noção do que pode ou não ser realizado em situaçóes de risco dita a possibilidade de sobrevida da vítima, redução nos casos de eventos adversos relacionados ao primeiro atendimento realizado sem conhecimento, dentre outras situaçóes.

Os participantes seguem comentando sobre as noçóes de medicina de tráfego e primeiros socorros apresentadas em sala de aula, conferindo ênfase para a maneira de como se portar em cenário de acidentes. O participante IT5 descreve: Neste módulo aprendemos várias situaçóes de como se comportar em um eventual acidente, seja ele causado por algum meio, um mal súbito, desmaio, mal estar e diversas situaçóes para assim termos o melhor controle. $\mathrm{E}$ ainda complementa: $O$ aprendizado que fica será utilizado sempre que nos depararmos com essa situação.

Desta forma, os conteúdos permanecem à disposição em caso de ocorrência de situaçôes adversas, conforme segue IT12: Como o instrutor de trânsito é um profissional que o ambiente de trabalho é na maioria das vezes em via pública pode 
estar exposto a acidente e incidentes a todo o momento. $\mathrm{O}$ mesmo participante ainda comenta sobre a diferença que o conteúdo faz para a formação do profissional: Sendo assim, o conteúdo trabalhado no módulo de noçóes de primeiros socorros e medicina de tráfego irá nos auxiliar muito quando nos depararmos com algum acontecimento que demande deste conhecimento.

E por fim, o mesmo participante comenta ainda que na prática diária, o instrutor de trânsito pode vir a necessitar destes conhecimentos para desenvolver as suas atividades, conforme o trecho a seguir: E mesmo em sala de aula, haverá talvez um aluno que poderá ter um mal súbito e as técnicas passadas proporcionarão um socorro rápido. Segundo Corrêa (2017), o instrutor de trânsito é um profissional que vivencia os riscos do trânsito diariamente nas conduçóes de aulas práticas em CFCs, demonstrando desta forma a necessidade de que os conteúdos básicos de primeiros socorros façam parte do currículo acadêmico.

Alguns cenários também foram mencionados pelos participantes da pesquisa, indicando que o conteúdo apresentado na disciplina faz a diferença na ocorrência de diversas situações além daquelas que normalmente enfrenta o instrutor de trânsito em sua atuação. Tal relato foi realizado por IT13: Muito interessante o conteúdo para o nosso dia a dia termos o conhecimento de como prestar o socorro para a vítima não só de acidente de trânsito, mas também acidentes domésticos.

Além dos acidentes domésticos, o instrutor de trânsito está capacitado para auxiliar em outros procedimentos, como o de remoção da vítima, citado por IT8: Este conteúdo é importante, pois ele vai fazer com que o instrutor de trânsito saiba se portar em uma situaçáo como mostrada em aula e que seja necessário socorrer e remover um acidentado. Para Araújo e Teixeira (2010) o instrutor de trânsito é o profissional responsável por guiar os futuros condutores para a prática segura, desta forma, além de ensinar, o mesmo necessita aplicar o seu conhecimento perante a comunidade, fortalecendo o vínculo e a responsabilidade como referência no tema.

Sob o mesmo limiar, os participantes mencionam a necessidade dos conteúdos em relação à formaçáo do instrutor de trânsito, conforme IT9 cita: Aprender a lidar com ocorrências em acidentes, sinalizar corretamente, prestando os primeiros socorros sem por a vítima em perigo, cuidando da sua própria segurança. O mesmo participante cita ainda a importância de aprender mais sobre os sinais vitais: Incluindo também a medição dos sinais vitais, controlando o bem-estar da vítima. Da mesma forma, o participante IT8 registra: Nossa profissáa possui risco para a ocorrência de acidentes, e os conteúdos aprendidos no módulo de primeiros socorros farão muita diferença na atuação desta área. $\mathrm{O}$ mesmo deixa explicito em seu relato a permanência destas práticas para o instrutor de trânsito: Pois assim, temos a noção do que fazer em relação à vítima e quando nos deparamos com um acidente. E por fim, o participante IT1 relata:

Certamente é muito importante este tema para a função de instrutor de trânsito, pois este é uma referência para a sociedade no que se trata de assuntos de trânsito. É fundamental ter essa noção, já que o dia a dia do instrutor 
é diretamente no trânsito e onde a maioria dos acidentes com lesôes graves acontece (IT1).

Em suma, saber qual atitude tomar em momentos de necessidade é a base para o conhecimento passado na disciplina, fazendo com que a reflexão permeie a formaçáo integral do profissional. Para Lima et al. (2021), o conteúdo de primeiros socorros é um amplo campo para ser explorado no ensino, principalmente quando é aliado a teoria e prática acadêmica, fortalecendo a experimentação e a necessidade constante de atualização profissional. Da mesma forma, Tebaldi e Ferreira (2004) comentam sobre a autoridade que o instrutor de trânsito exerce no contexto de segurança do trânsito, englobando assim a realização de práticas de saúde em relação a situaçôes de urgências e emergências.

\section{$O$ instrutor de trânsito enquanto formador de condutores}

Esta subseção identifica um contexto pouco explorado na literatura, que é a função docente do instrutor de trânsito, fato que se concretiza nas aulas teóricas e práticas desenvolvidas nos CFCs. Os pontos aqui identificados convergem na capacidade e importância do instrutor de trânsito ensinar os seus alunos sobre medicina de tráfego e primeiros socorros.

Os participantes da pesquisa mencionam a importância de ensinar e preparar os estudantes em relaçáo à prática de medicina de tráfego e primeiros socorros, conforme pode ser identificado no trecho relatado por IT7: É importante pois nós e nossos alunos, podemos nos deparar com um acidente e sabermos como reagir diante desta situação e assim saberemos como salvar uma vida. Não é somente o que fazer, mas qual é o comportamento desejado para o condutor em cenário de crise, conforme pode ser verificado no relato de IT 2: Para o instrutor de trânsito é importante náo apenas como se comportar no caso de um acidente, mas saber como orientar os seus alunos continuamente. $\mathrm{O}$ mesmo participante continua: A contribuição para o instrutor de trânsito é de relevância incrivel e indispensável, pois são práticas que podem salvar vidas. Para Carneiro e Faria (2017) o instrutor de trânsito possui importância fundamental para a formaçáo dos futuros condutores de veículos, indicando pontos de risco e a possibilidade de realizar açóes de prevençáo e cuidado em saúde.

A possibilidade de auxiliar a vítima em casos de acidentes é a principal justificativa para os participantes em ensinar os conteúdos para os seus alunos, como IT1 cita: Como instrutor de trânsito os conteúdos abordados são de segurança e ensino em caso de acidente. E ainda, IT3 registra: As técnicas aprendidas certamente fazem a diferença no desenrolar da situação, podendo aumentar muito a chance da vítima a sobreviver. $\mathrm{O}$ mesmo participante afirma que a possibilidade de salvar vidas justifica a aprendizagem do conteúdo: Os métodos ensinados ao instrutor de trânsito certamente ajudam a salvar vidas. Ao desenvolver práticas de primeiros socorros o indivíduo demonstra a autonomia necessária para executar certas açóes e procedimentos que podem salvar vidas, ou reduzir drasticamente a possibilidade de agravos ou situaçôes de negligência ou imprudência (SANTOS DIAS et al., 2021). 
A noçáo de que o conhecimento sobre primeiros socorros e verificaçáo de sinais vitais não serve somente para a prática profissional, mas também para a vida, pode ser verificado no trecho abaixo registrado por IT6:

Para mim foi muito importante, pois como instrutor de trânsito, devo saber como agir com os alunos em caso de precisar socorrer alguém. Acredito que não somente como instrutor, mas para a vida, saber auxiliar em casos de emergência é muito importante, tanto em casa, quanto na rua e claro também durante as aulas. Ter noçóes de imobilização, desengasgar e aprender a verificar a pressão arterial serão imensamente importantes para a vida, e claro que todo o conteúdo tratado e exemplos de acidentes, podem acontecer no dia-a-dia (IT6).

Da mesma forma, o dever profissional aparece no relato de IT2: Podemos ensinar os nossos alunos a como eles devem agir em determinadas situaçôes, assim como para nós mesmos em caso de necessidade, incluindo na sala de aula, no veículo e na rua. E o mesmo participante cita ainda a qualificaçáo do trabalho quando consegue realizar as ações aprendidas: Assim, é possivel prestar um bom trabalho, tanto para a pessoa que recebeu os primeiros socorros, quanto para o indivíduo. Em suma, Vasconcellos Piscoya et al. (2021) retomam o fundamento de que realizar o primeiro atendimento é um ato extremamente ligado com o dever humano de solidariedade com um indivíduo igual, inferindo que neste contexto, mesmo náo havendo o conhecimento especializado, algumas ações como a de sinalizar o local e chamar por socorro podem ser realizados por qualquer indivíduo.

A consciência sobre a importância do instrutor de trânsito para a formação do condutor é verificada nos relatos dos participantes, de modo que os conteúdos de medicina de tráfego e primeiros socorros compõem o manejo correto das situações de risco, conforme indicam IT11: São inúmeras as contribuiçôes, desde a forma de lidar com o nosso aluno, até chegar ao trânsito. Quando estamos no trânsito, são muitas as situaçóes de perigo, imprudência e negligencia que acontecem.

O participante IT07 descreve: $O$ instrutor de trânsito tem a obrigaçâo de formar condutores preparados e conscientes a zelar pela vida e proteção do nosso ambiente em geral. Nas consideraçóes de Caetano et al. (2021) e de Moreira (2010), o instrutor de trânsito possui a responsabilidade de transformar a visão do condutor perante o meio, para que quando formado exerça sua real atribuição de maneira segura e condizente com a legislação nacional, prezando pela segurança e bem-estar da população.

\section{CONSIDERAÇÓES FINAIS}

Compreende-se que este estudo cumpriu com o seu objetivo de relatar a experiência de enfermeiros na inserção da disciplina de medicina de tráfego e primeiros socorros em um curso de formação de instrutores de trânsito promovendo uma reflexão sólida acerca dos aspectos que permeiam a formação integral deste profissional. 
Evidencia-se que a atuação do enfermeiro se traduz em uma contribuição essencial para os futuros instrutores de trânsito, uma vez que proporciona conhecimentos diretamente relacionados à prática profissional, promovendo subsídios teóricos e práticos para açôes de prevenção de acidentes, promoção de um trânsito mais seguro e açóes de primeiros socorros a fim de minimizar a ocorrência de novos acidentes, auxiliando nas açóes de remoção e transporte adequados aos envolvidos.

Sugere-se que novos estudos possam ser realizados subsidiando a formulação de estratégias e políticas direcionadas a melhoria das condiçóes de trabalho desta categoria profissional. Para, além disso, proporcionar ao cidadáo, que ora ocupa a posiçáo de condutor e ora de pedestre, a possibilidade de salvar vidas, e/ou reduzir drasticamente a possibilidade de agravos ou situaçôes de negligência ou imprudência.

\section{REFERÊNCIAS}

ADURA, F.; GIANVECCHIO, D.; MUÑOZ, D. R. Medicina de tráfego. Revista de Medicina, v. 9, n. 1, p. 14-15, 2012.

ALVES, J. D. R. Repercussão do sono sobre o trabalho. Diagn Tratamento, v. 15, n. 3, p. 150-2, 2010.

ARAÚJO, E. G.; TEIXEIRA, M. C. Relacionamento com colaboradores: compreendendo as necessidades. Ciência \& Consciência, v. 1, 2010.

ARAÚJO, K. B. Treinamento de instrutores de trânsito: um estudo de caso junto a um centro de formaçáo de condutores. Trabalho de Conclusão de Curso de Graduação. 2014.

BARDIN, L. Análise de Conteúdo. Tradução: Luís Augusto Pinheiro. São Paulo: Ediçóes 70. 2016.

CAETANO, B. G. et al. Proposta de intervenção para intervenção para capacitação em primeiros socorros em engasgamento relacionado á aspiração de corpo estranho (ace) em crianças de 0 a 06 anos. Mostra de Inovaçáo e Tecnologia Sáo Lucas, v. 1, n. 2, 2021.

CARNEIRO, F. B.; FARIA, R. R. Psicologia do trânsito. Psicologia Argumento, v. 25, n. 51, p. 345-347, 2017.

CORREAA, D. M. Análise ergonômica do trabalho de instrutores práticos de uma autoescola do sul de Santa Catarina: estudo de caso. Trabalho de Conclusão de Curso de Especialização em Engenharia de Segurança do Trabalho-Tubarão, 2017.

DIAS, E. S. et al. Elaboração de material informativo para prestar primeiros socorros em cortes e contusôes: relato de experiencia. Mostra de Inovaçáo e Tecnologia Sáo Lucas, v. 1, n. 2, 2021. 
FENELON, G. et al. Brazilian guidelines for automobile driving in patients with implantable cardiac electronic devices and cardiac arrhythmias. Arquivos brasileiros de cardiologia, v. 99, n. 4, p. 1-10, 2012.

GOI, E. A.; GOI, M. E. J. A educação para o trânsito: uma temática a ser trabalhada na experimentação em química. Research, Society and Development, v. 9, n. 3, p. 1-14, 2020.

LIMA, M. M. S, et al. Intervenção educativa para aquisição de conhecimento sobre primeiros socorros: revisão integrativa. Enfermagem em Foco, v. 12, n. 1, p. 147-53, 2021.

Lima, P. A. Primeiros socorros como objeto de educação em saúde para profissionais de escolas municipais. Revista de Enfermagem da UFSM, v. 11, p. 1-16, 2021.

MELLO, F. R. Municipalização do trânsito em Taubaté/SP. Trabalho de Conclusão de Curso de Especialização em Gestão de Trânsito-Unisul Virtual, 2017.

MORAES, R. B. A. R. et al. Primeiros Socorros: o ensino das práticas básicas por meio das redes sociais. Mostra de Inovaçáo e Tecnologia Sáo Lucas, v. 1, n. 2, 2021.

MOREIRA, A. D. Educação de trânsito. Sínteses: Revista Eletrônica do SimTec, v. 3, p. 269-270, 2010.

PEREIRA, C. M. S. B. et al. Avaliação do conhecimento em primeiros socorros de alunos das autoescolas de Vassouras. Revista Eletrônica Acervo Saúde, v. 13, n. 4, p.1-9, 2021.

PERES, P. S. Q et al. Atuação do enfermeiro em um serviço de atendimento préhospitalar privado. Rev Fund Care Online, v. 10, n. 2, p. 413-422, 2018.

PISCOYA, G. V. et al. O projeto "Primeiros Socorros nas Escolas" e o COVID-19: relato de experiência. Revista de Extensáo da UPE, v. 6, n. esp, p. 33-39, 2021.

PISSAIA, L. P.; COSTA, A. E. K. Saúde e segurança: reflexões sobre a formação do instrutor de trânsito. Research, Society and Development, v. 8, n. 9, p. 1-14, 2019

PISSAIA, L. P.; COSTA, A. E. K. Medicina de tráfego e primeiros socorros: interlocuçóes com a formação do instrutor de trânsito. Research, Society and Development, v. 9, 3, p. $1-14,2020$.

SILVA, M. OYAMA, S. M. M.; SANCHEZ, F. F. S. Dispositivos de segurança para crianças em veículos motorizados: Prevenção de morbimortalidade. Perspectivas Médicas, v. 27, n. 2, p. 9-15, 2016.

SILVA, T. L. et al. Metodologia da problematização no ensino de primeiros socorros para crianças na escola: relato de experiência. Revista Enfermagem Atual In Derme, v. 95, n. 35 , p. $1-11,2021$.

TEBALDI, E.; FERREIRA, V. R. T. Comportamentos no trânsito e causas da agressividade. Revista de Psicologia da UNC, v. 2, n. 1.p, 15-22. 